\title{
Increased Productivity through Dynamic Process Optimization in Sterile Facility 303 at Novartis Pharma Stein AG
}

\section{A. Introduction}

\author{
Peter Nyfeler
}

\begin{abstract}
Pharmaceutical production processes are subject to a multiplicity of regulatory requirements regarding the product quality. Since economic aspects (e.g. productivity) also have to be considered, process optimizations have to be carried out. In Building 303 at Novartis Pharma Stein AG new technologies have been implemented, which are constantly reviewed and optimized to increase the productivity and to keep up with the state of the art and the requirements.
\end{abstract}

Keywords: Maximization of production output · Pharmaceutical production $\cdot$ Regulatory requirements

The subsequent four articles

- 'Dynamic Study of Filling Weight Deviations on a Vial-Filling Machine'

- 'Installation of a Camera for Ampoule Burn Marks in Sterile Facility Building $303^{\prime}$

- 'Heat Transfer Coefficient in the Shelves of a Freeze Dryer'

- 'Removal of Glass Tips in Pharmaceutical Production'

show examples how, in pharmaceutical production, companies have been able to establish themselves as leaders in their sector thanks to new technologies. The technological standing of a company can thus be crucial in deciding whether it is a success or a failure. Particular attention should therefore be paid to the selection, development and operation of new technologies. A precondi-

${ }^{*}$ Correspondence: P. Nyfeler, Dipl. Masch. Ing. HTL Novartis Pharma Stein AG

Plant Engineering Sterile Forms

Schaffhauserstrasse

$\mathrm{CH}-4332$ Stein

Tel.: + 41628687411

Fax: + 41628687465

E-Mail: peter.nyfeler@pharma.novartis.com

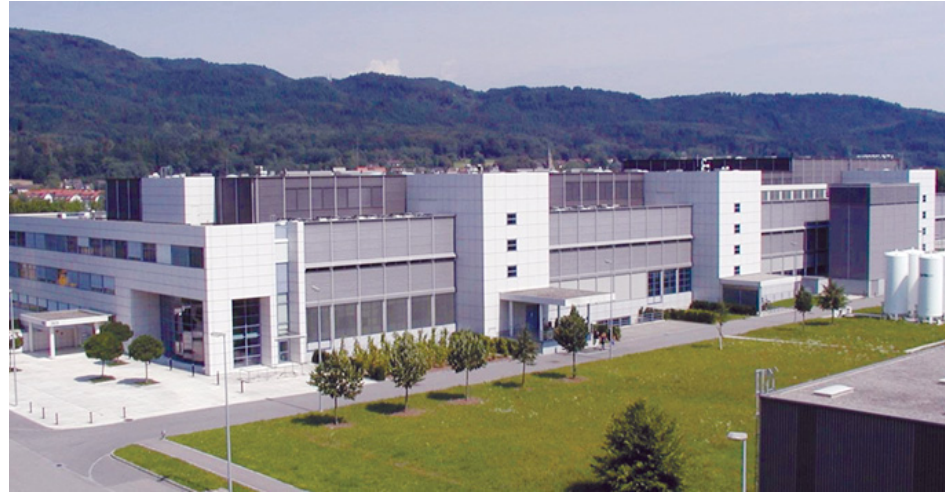

Fig. 1. Sterile Facility 303

tion for the use of new technology, however, is to have a good command of the production processes.

Manufacturers of pharmaceutical products are constantly under pressure not only to maximize production output but at the same time to comply at all times with regulatory requirements and quality standards. The demand for especially reliable and long-lived production processes is high and steadily increasing. A process is reliable when it runs without any problems for as long as possible. In Sterile Facility 303 (Fig. 1), the processes were 'validated' when the new equipment was started up, i.e. we showed evidence that the required quality of the 'products' can be reliably achieved. We generate a body of data in the individual process steps and thus monitor the limits and the quality of the products. If the values obtained fall outside the limits, deviation reports are drawn up and the cause is analyzed (usually at relatively high 'cost').

The ability of a process to meet the stipulated quality requirements with regard to the manufactured product is expressed through its so-called process capability. GMP and proven conformity to quality standards are based on a sound (correct) decision-making process, which in turn is based on the data collected from all the batches manufactured, starting with the raw materials right through to the end-product. Through specific processing and evaluation of the data obtained, process-relevant data can be generated under the various production batches with the aim of minimizing 
losses. The key figures calculated for this purpose indicate the level of reliability with which the process results in products that lie within the stipulated specifications. A prerequisite for the determination of process capability is that the process is under control, i.e. the process or sub-processes have to be free from specific, systematic influences.
An optimization of our processes and thus an increase in productivity can be achieved in this way.

We would like to show by means of some examples how the production processes at Novartis Pharma Stein AG are constantly being reviewed and optimized to ensure at the same time that they match the current state of the art. First and foremost, efforts are invested in those technologies which are the most attractive possible and which offer relative strengths for further development and application in our production processes.

\title{
B. Dynamic Study of Filling Weight Deviations on a Vial-Filling Machine
}

\author{
Peter Nyfeler*
}

\begin{abstract}
Strict requirements are imposed on pharmaceutical products in terms of dosing and thereby high demands with regard to filling weights. State-of-the-art filling technology is commercially available. But a certain disenchantment comes with the production processes, i.e. with the properties of the products, the quality requirements and the GMP and validation specifications. The purpose of this study was to analyze the causes of filling weight deviations on a vial-filling machine using a time/pressure filling system and to optimize the dosing of the weight. The study was carried out on a $100 \mathrm{ml}$ vial-filling process, including the automatic CIP/SIP cleaning process. The filling process was described in a mathematical model and the qualitative conclusions were confirmed by means of filling tests. In a further step, optimization procedures were simulated in a dosing element and the reliability of the weight dosing was checked.
\end{abstract}

Keywords: Dynamic control · Vial filling weight

\section{The Nature of the Study}

As shown in Fig. 1, the filling process is carried out using a time/pressure filling system. The system pressure in vessel 1 is kept constant by means of a control device. The level in the vessel is likewise kept constant, and at the same time the immersion pipe of the product line is designed in such a way that no wave motion

${ }^{\star}$ Correspondence: P. Nyfeler, Dipl. Masch. Ing. HTL Novartis Pharma Stein AG

Plant Engineering Sterile Forms

Schaffhauserstrasse

$\mathrm{CH}-4332$ Stein

Tel.: + 41628687411

Fax: + 41628687465

E-Mail: peter.nyfeler@pharma.novartis.com

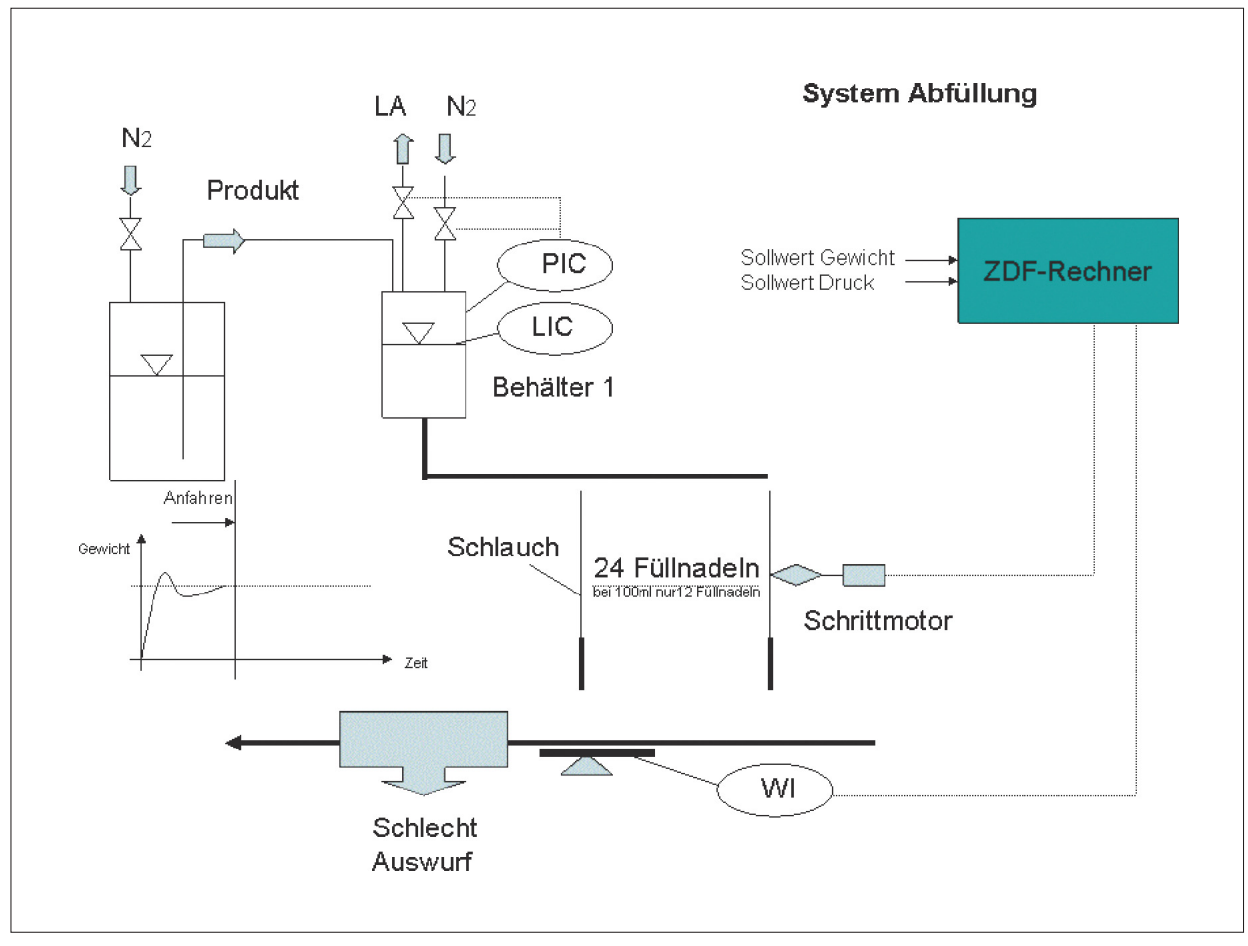

Fig. 1. Principle of filling installation 


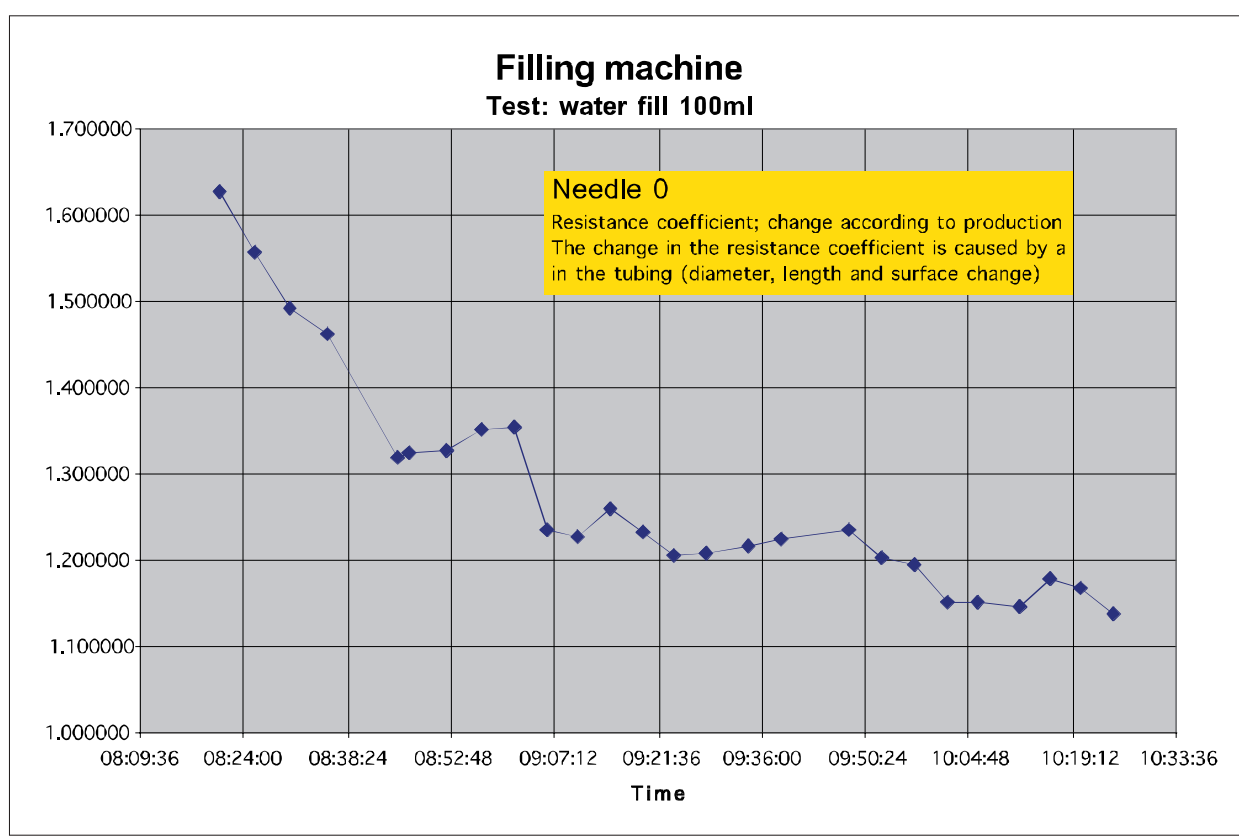

Fig. 2. Change in resistance coefficient as a function of process time

\section{Filling machine Test: water fill $100 \mathrm{ml}$}

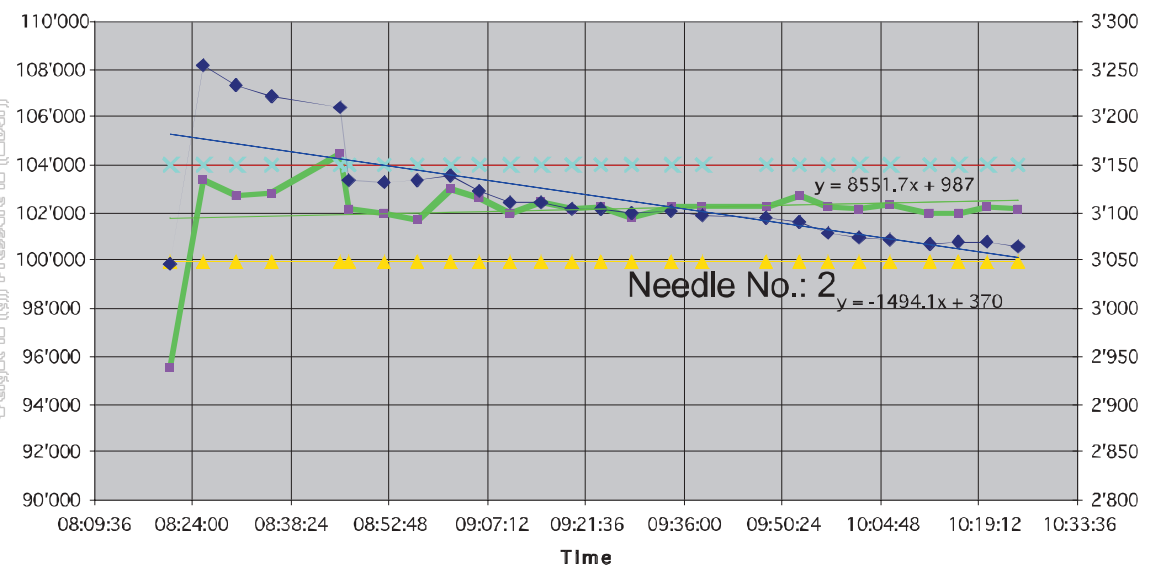

$\Longrightarrow-$ Gewicht $\_-\min \longrightarrow *-\max \longrightarrow$ Dosierzeit —- Linear (Gewicht) — Linear (Dosierzeit

Fig. 3. Change in weight, dosing time as function of process time vomotor is opened, pressure builds up as a result of the baffle in front of the filling needle, which widens the tubing. The effect of the pressure on the tubing over time and thus the material stress depends on the size of the format. After the servomotor is closed, this pressure falls and the tube retracts again, i.e. the volume in the tube changes (pump action). The strength properties of the tubing change depending on the period of exposure to this stress.

The dosing element of the control system must offset these disturbances. The function of the control line of the weight dosing system is not constant and must therefore adapt to the change in the tubing properties. The pressure regulation on the intermediate storage vessel is stable and constant. The level regulation system in the buffer vessel shows a control deviation of about $3 \mathrm{~mm}$ liquid level. Thanks to the shape of the filling pipe, the surface of the liquid in the intermediate storage vessel cannot be made to 'vibrate' and can thus also not exert any adverse dynamic effects on the control circuit (Fig. 1).

The evaluation of the test run is shown in Fig. 2 (change in coefficient resistance with a constant fill quantity over the whole test period) and Fig. 3 (total water run for needle 2 (machine protocol)).

\section{Solution to the Problem}

In a first step, a search was made for optimum tubing material. The existing tubes are validated with the filling process (incl. cleaning validation) and at the same time the manufacturing process for the pharmaceutical product is registered with the authorities, such as the FDA. A quality improvement in the tubes is very expensive and cannot be achieved within a reasonable period. In a second step, we therefore lengthened the filling needles and thus shortened the tubes, thereby reducing the undesirable characteristics of the tube (Fig. 4). can occur in vessel 1 . The formats $6 \mathrm{ml}$ to $100 \mathrm{ml}$ vials (sterile in cleanroom zone A) are filled on the machine. The required weight tolerances are declared to be $<2 \%$. During the test run (wet run using water) with $100 \mathrm{ml}$ vials (machine run time from $8: 46$ a.m. to $10: 24$ a.m.) the tubing changed in such a way that the dosing time (opening of the valve) had to be reduced by $>7 \%(188 \mathrm{~ms})$ in order to meet the nominal filling volume at constant pressure and temperature. The test run was carried out immediately after the CIP/SIP cleaning process. The most likely cause is to be found in the tubing material, i.e. in the elasticity and thus in the change of flow resistance. When the ser-

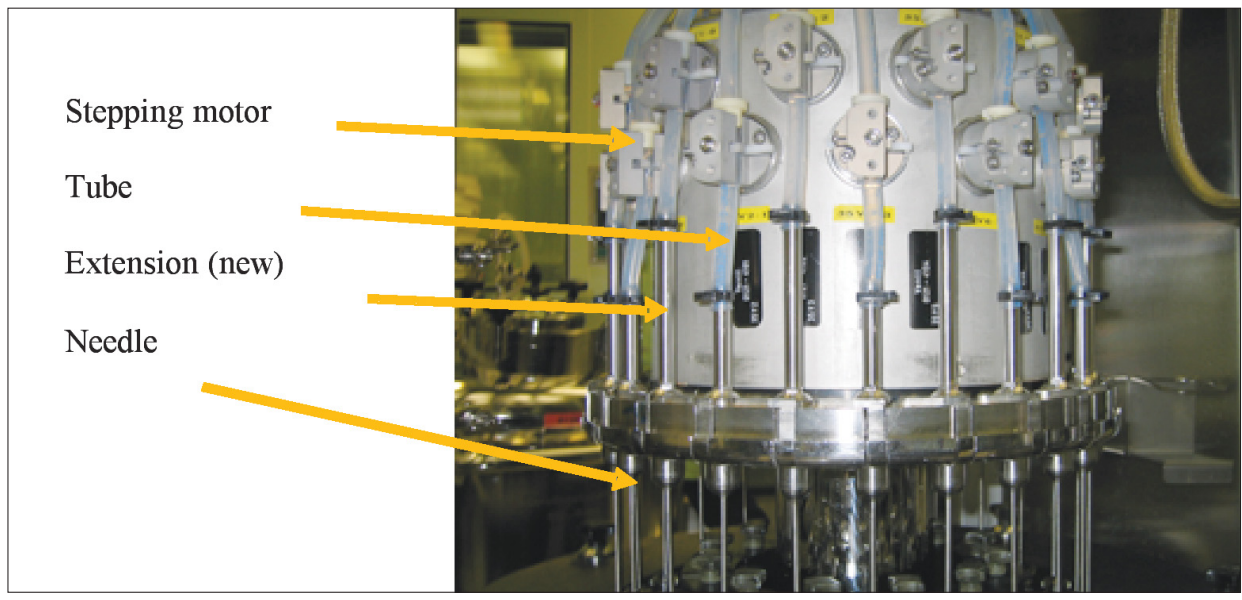

Fig. 4. Filling needles with servomotors 


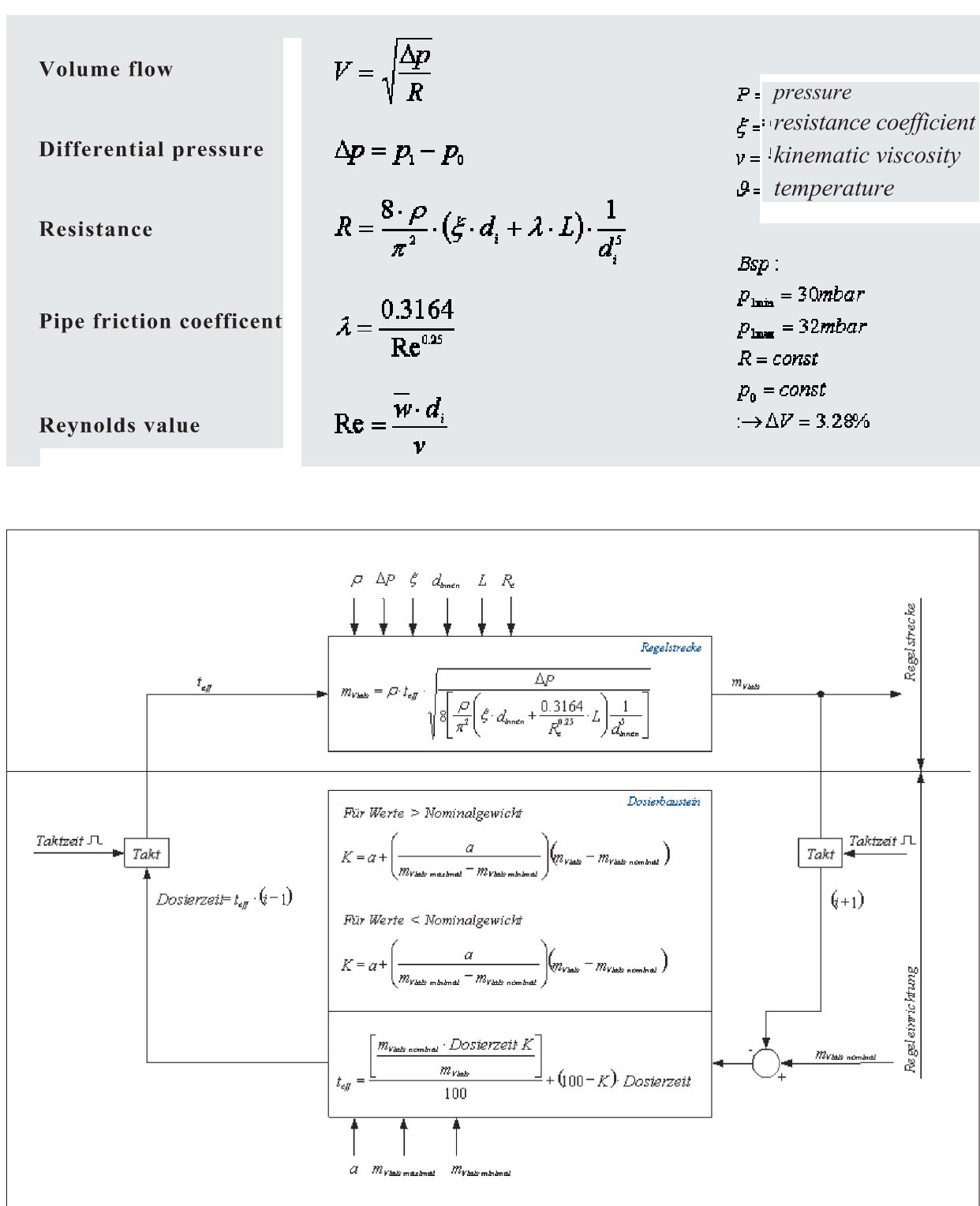

Fig. 5. Mathematical description of the filling process

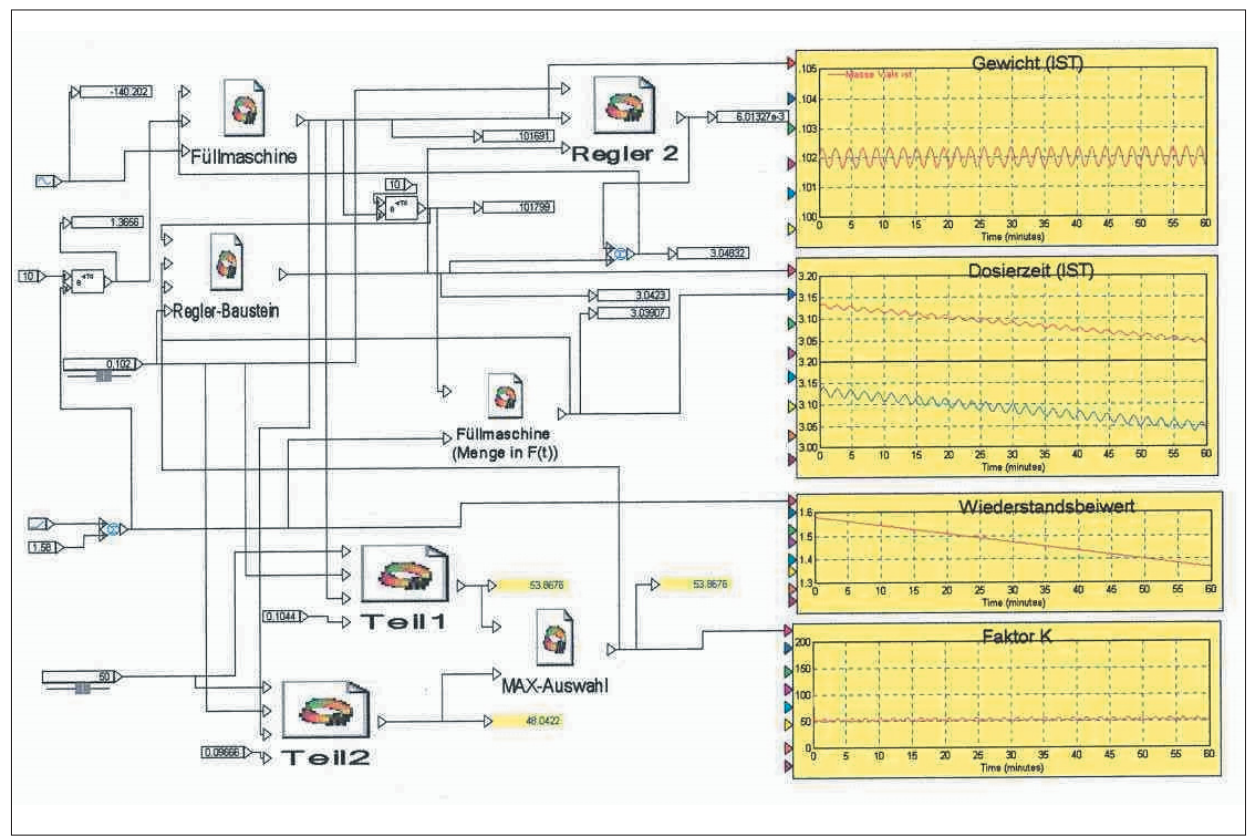

\section{Physical Principle}

According to Bernoulli's law, there is a correlation between the cross-section of the filling needles, the tube and the pressure prevailing therein. The total static and dynamic pressure is constant in a stationary flow.

\section{Mathematical Description of the Filling Process}

Simulation is nothing more than the most systematic possible series of real assumptions about a functioning system. Mathematical models are usually a set of differential equations and functional relationships that allow a prediction to be made about the time course of physical processes. In process engineering, one seeks to achieve models which can be brought into line in their prediction of the measurement results, but whose structure also reflects that of the process (structure-true models). The nature of the task formulated in words must now be rendered in the form of a mathematical relation, where particular attention must be paid to the fact that the secondary conditions mentioned also have to be properly registered. The starting point for any mechanical calculation is a clear formulation of the task in hand (Fig. 5).

\section{Simulation}

The Vis-Sim Mathcad program was used for the simulation. Fig. 6 shows the structure of the simulation. During the simulation, the pressure was varied by about $10 \%$. With the optimization of the control elements (controller 2, part 1 and part 2) and shortening of the tubes, the scatter of the filling weights can be markedly reduced.

\section{Vision}

The possibility of switching to a dosing system with a 'neuro fuzzy system' is currently under consideration. The advantage is that the knowledge remains available in the form of rules and all modifications that are introduced into the system by training can be reconstructed directly in the knowledge base. The transparency of the system leads to a number of advantages in its application:

- Prior knowledge can be entered into the system without problems before the learning process (production process)

- Manual interventions in learning process are possible, especially when there are changes in product characteristics

- Any aberration in the operational phase remains explicable and can be remedied through a targeted manual intervention

Received: July 2, 2004 


\title{
Specification
}

\section{Data: Filling Process}

The weight limits used in the water fill correspond to the filling volume limits of the product $(102.00 \mathrm{ml}+/-2 \%$ tolerance limits, or $103.480 \mathrm{~g}+/-2 \%$

\begin{tabular}{|l|l|l|}
\hline \multicolumn{2}{|c|}{ Water run } & \\
\hline Fill quantity $[\mathrm{g}]$ & Density: water & Density product: $1.0145 \mathrm{~kg} / \mathrm{dm} 3$ \\
\cline { 2 - 3 } minimum & 99.9600 & 101.41 \\
nominal & 102.0000 & 103.48 \\
maximum & 104.0400 & 105.55 \\
\hline Smallest dosing unit $1 \mathrm{~ms}=0.0346 \mathrm{~g}$ & \\
with unchanging resistance coefficient (no change in tube) & \\
Range of span width [g] $\quad 4.08$ & \\
Dosing time [ms] (for range) & 117 & \\
\hline
\end{tabular}

Change in resistance coefficient (regression equation from water run)

Loading time

Start 27.02.2004, 08.16.31

End 27.02.2004, 10.30.15

Resistance coefficient start

Resistance coefficient end

1.634584

Weight [g]

95.5932

Dosing time [ms]

1.139139 Weight $[\mathrm{gl} \quad 102.1561 \quad$ Dosing time $[\mathrm{ms}]$

Weight $[\mathrm{g}]$

6.5629

Dosing time $[\mathrm{ms}]$

Difference

\begin{tabular}{|ll}
\hline Change in tube properties (resistance coefficient) during filling time (machine running time) \\
Range of span width $[\mathrm{g}]$ & 4.0800 \\
Difference $[\mathrm{g}]$ & 6.5629 \\
Drift towards span width & $160.86 \%$ \\
\hline
\end{tabular}

\section{Installation of a Camera for Ampoule Burn Marks in Sterile Facility Building 303}

\author{
Antonio Zeoli*
}

\begin{abstract}
On the DRN code-ringing machine, a system was installed and qualified in November 2001 for the detection of burn marks in ampoule tips. Since the ampoules are ringed immediately after sealing, and the burn marks are thus covered up, inspection is only possible between these two steps. This installation monitors the product quality online, so that the system does not have to wait until the inspection procession before detecting an accumulation of burn marks, but displays them immediately in order for countermeasures to be taken. The camera for burn marks is a tool for the early detection of malfunctions and minimization of rejects.
\end{abstract}

Keywords: Camera for burn marks · DRN code-ringing

${ }^{*}$ Correspondence: A. Zeoli, Dipl. Masch. Ing. FH Novartis Pharma Stein AG

Plant Engineering Sterile Forms

Schaffhauserstrasse

$\mathrm{CH}-4332$ Stein

Tel.: + 41628686213

Fax: + 41628687465

E-Mail: antonio.zeoli@pharma.novartis.com

\section{Background Information/Generation of Burn Marks}

After cleaning, sterilization, and filling of ampoules on the ampoule production lines in Building 303, the ampoules are sealed by means of a gas flame at a temperature of about $1200{ }^{\circ} \mathrm{C}$. During the filling process, it can happen that the filling needle touches the neck of the ampoule on immersion - as a re- sult of tolerances in the symmetry of the ampoules - and leaves behind product residues on the ampoule. These product residues then become charred during the subsequent sealing process, when the tip of the ampoule is melted, and remain visible as dark-gray specks in this part of the ampoule. This phenomenon occurs especially with products in relatively high concentration (Fig. 1 and 2). 


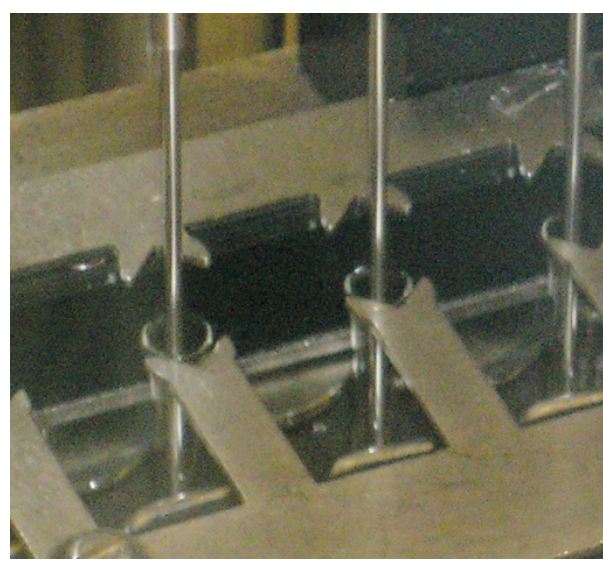

Fig. 1. Immersion of filling needle into the ampoule

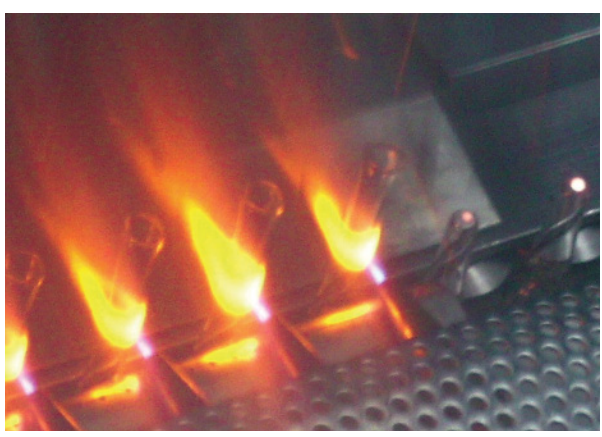

Fig. 2. Sealing of ampoule

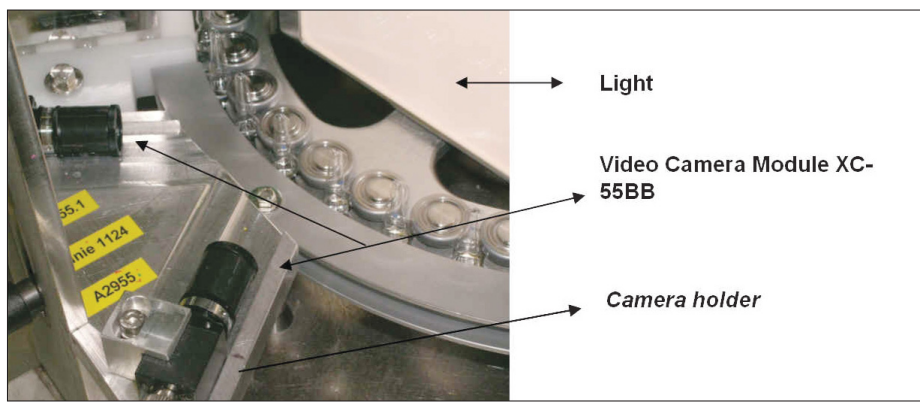

Fig. 3: Camera layout on DRN ringing machine

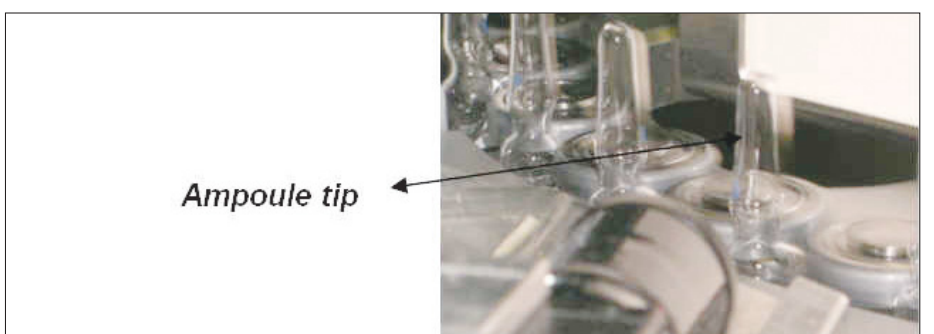

Fig. 4. Ampoule in inspection line

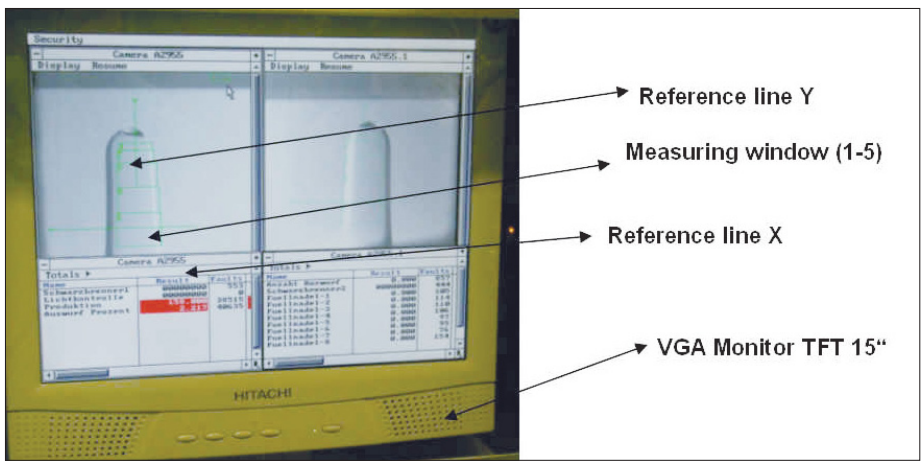

Fig. 6. System display

\section{Problem/Solution}

Burn marks come under the heading of cosmetic defects and are checked on the downstream inspection machine, from EISAI, by means of a CVIM camera. A complicating factor here is that, after filling and sealing, the ampoules are provided with ring codes around the tip end for the purposes of identification, and burn marks that may lie in the region of the bar code cannot by picked up by the EISAI inspection machine.

\section{Technical Solution}

With an Allen-Bradley CVIM2 camera module and a SPS Siemens 95U, burn marks at the tip end of the ampoules are detected and sorted out by means of two model Sony XC-55BB cameras.

The cameras are pointed at a light from an angle of $45^{\circ} / 135^{\circ}$. This assembly with light transmitted through the tip end of the ampoules enables them to be checked for burn marks up to a size of about $0.2 \mathrm{~mm}$.

By means of an angle of rotation sensor, the exact position of the ampoule in front of

the cameras is transmitted via input 1 (trigger) to the camera module. Using the software module in CVIM2, the position of the measuring windows (1-5) in the ampoule tip is located first with reference line X then Y, and in the measuring windows a pixel comparison is now made between white and black. The result is transmitted to the output unit by means of the adjusted range. The SPS receives this signal and sends the information (high = good ampoule/low = bad ampoule) to the position in the discharge compartment attached to the discharge worm (dual function with IPC), see Fig. 3, 4, 5 and 6.

\section{System Construction and \\ Performance Data}

\section{Installation in Stainless-Steel PC \\ Cabinet from Rittal}

- Camera system Allen-Bradley CVIM2 with 6 camera input modules/digital IO modules

- VGA Monitor TFT 15", operating unit series mouse

- Siemens SPS 95U with interface to pulse encoder of filling line (digital)

Location of Assembly DRN Ringing Equipment

- 2 Sony XC-55BB video camera modules consisting of two parts (head unit) (control unit)

- Homogeneous light

- Camera holder

- The system offers a possible throughput of 400 ampoules/min (Fig. 7)

Received: July 2, 2004

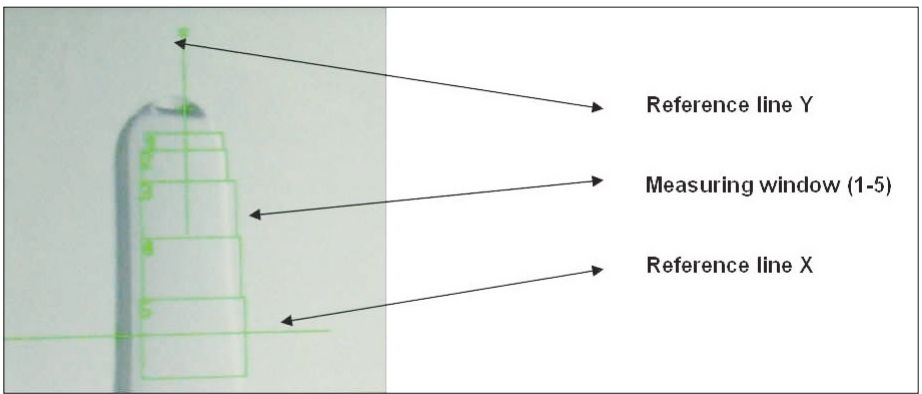

Fig. 5. Control window in ampoule tip

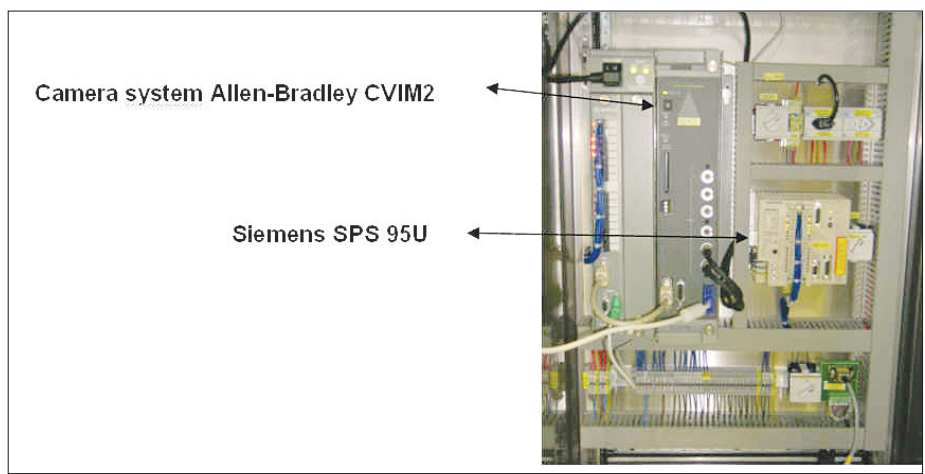

Fig. 7. Control system 


\title{
D. Heat Transfer Coefficient in the Shelves of a Freeze Dryer
}

\author{
Cédric Bokalot ${ }^{\mathrm{a}}$ and Peter Nyfeler ${ }^{\star}$
}

\begin{abstract}
The aim of this study is the determination of the heat transfer in the shelves of a freeze dryer. The inner geometry of the shelves is a long rectangular duct, which guides the heat fluid specifically inside the shelf. The heat transfer from fluid to the inner wall of the rectangular duct based on the energy and heat balances for a stationary process and an uniform temperature distribution over the shelves is deduced. The calculation of the heat-transfer coefficient by convection within the channel of a plate is performed and provides a formula valid for all shelves with rectangular ducts. Measurements on a freeze dryer with $20 \mathrm{~m}^{2}$ of shelves surface result in a heat-transfer coefficient of $214 \frac{\mathrm{W}}{\mathrm{m}^{2} \cdot \mathrm{K}}$ at $-45^{\circ} \mathrm{C}$ up to $792 \frac{\mathrm{W}}{\mathrm{m}^{2} \cdot \mathrm{K}}$ at $15^{\circ} \mathrm{C}$. The determined $\alpha$ value is realistic and is in the same order of magnitude compared with the values determined in earlier studies. This study is to be seen as a partial contribution to the complete study of heat transfer between heat transfer medium and product within the vials during freeze drying.
\end{abstract}

Keywords: Freeze dryer · Heat transfer coefficient by convection · Heat transfer in rectangular duct

In the pharmaceutical industry, the active substances contained in sterile dosage forms are often not stable in solution. To preserve the structure of the active substance during drying and to ensure that the dried form can be readily re-dissolved again, lyophilization is often used as the drying process. Freeze-drying involves several energy-intensive processes. Most products require low temperatures (down to less than $-45^{\circ} \mathrm{C}$ ) and a high vacuum to less than 1 mbar during drying. The processes may last about $24 \mathrm{~h}$ up to several days.

In sterile production at Novartis Pharma Stein AG, heat transfer between the heat transfer medium within the shelves of the freeze dryer and the product in the vials was investigated as part of a diploma dissertation. This article describes the heat transition from the coolant to the shelf.

${ }^{*}$ Correspondence: P. Nyfeler, Dipl. Masch. Ing. HTL Novartis Pharma Stein AG

Plant Engineering Sterile Forms

Schaffhauserstrasse

$\mathrm{CH}-4332$ Stein

Tel.: + 41628687411

Fax: + 41628687465

E-Mail: peter.nyfeler@pharma.novartis.com

${ }^{\mathrm{a} C}$. Bokalot, Dipl. Ing. TH

Chemgineering AG

Eptingerstrasse 41

CH-4132 Muttenz

E-Mail: cedric.bokalot@chemgineering.com

Part of C.B.'s dissertation 'Dynamic and thermody namic analysis of freeze-drying' under the supervision of Dipl.-Ing. P. Nyfeler, Head Plant Engineering

Sterile Forms at Novartis Pharma Stein AG.
The drying process in most cases is a sublimation of frozen water, i.e. of ice, and consists of four consecutive process steps: freezing, primary drying, secondary drying and follow-up treatment.

During freezing and primary drying, the capacity of the shelves for cooling the product is especially important. The heat transition is optimized by the selection of the heat transfer oil and the inner construction shape of the shelves. The selection of the heat transfer medium for the freeze-drying process is of utmost importance and should be undertaken bearing in mind all the appropriate factors. The relevant factors are the operating temperature range, operating safety, the corrosive properties of the heat transfer medium, energy consumption (resulting from loss of pressure), the explosion limits in air (explosion protection), and especially the heat transfer properties and vapor pressure (contamination of the product in the event of leakage) of the heat transfer medium.

The shelves are the most important part for heat exchange between the heat transfer medium and vials. A precise knowledge of the geometry is thus essential. Fig. 1 shows the schematic structure of a shelf. Every shelf consists of two base plates of sheet metal thickness $s$ and segments with a square-shaped cross-section that are welded onto the base plates in the shape of a 'coil'. These segments support the base plates against one another and allow the heat transfer medium to be specifically guided through the rectangular channels (Fig. 2). The base plates and the segments are made of stainless steel. In Fig. 2, $a$ rep-

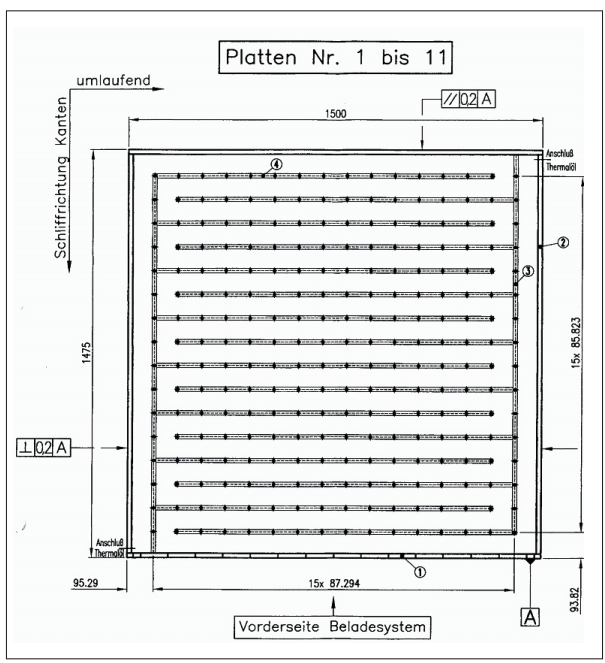

Fig. 1. Schematic diagram of a shelf

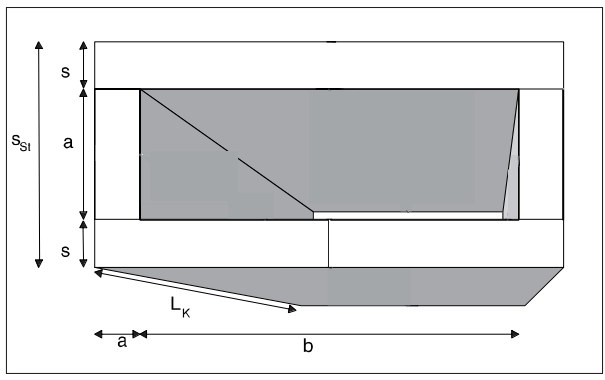

Fig. 2. Channel geometry

resents the height of the channel and the thickness of the channel wall, $s_{S t}$ is the overall height of the shelf, $s$ is the sheet metal thickness of the upper and lower base plate, 
$b$ is the width of the channel and $L_{K}$ the total length of the channel.

The heat transfer takes place in two different ways: firstly by heat conduction to the base plates and secondly through heat transitions resulting from convection between the sides of the channel and the heat transfer medium.

The coefficient of heat transfer through convection in the shelves was determined experimentally. Since certain fluctuations were observed in cooling from $15^{\circ} \mathrm{C}$ to -45 ${ }^{\circ} \mathrm{C}$, a linear regression of the measurement values was carried out in relation to the nominal temperature $T_{\text {nom }}$.

The first step in the calculation of the heat transfer coefficient by convection is to determine the transferred heat: The heat transfer medium is regarded as a system. The transferred heat is defined as follows according to the energy balance:

$$
Q_{W T R}=M_{P L} \cdot \int_{T_{E i n R}}^{T_{A u s R}} C p(T) d T
$$

In the above Eqn., $\mathrm{Q}_{\mathrm{WTR}}$ is the transferred heat $[\mathrm{J}]$ corrected by means of linear regression, $\mathrm{M}_{\mathrm{PL}}$ is the mass flow $[\mathrm{kg} / \mathrm{s}]$, $\mathrm{Cp}(\mathrm{T})$ the specific heat $[\mathrm{J} /(\mathrm{kg} . \mathrm{K})], T_{\text {EinR }}$ the corrected input temperature $[\mathrm{K}]$ and $T_{A u s R}$ the corrected output temperature $[\mathrm{K}]$.

During the cooling of the chamber (i.e. while the product is being frozen) heat is transferred from the product to the heat transfer medium and is $\mathrm{Q}_{\mathrm{WTR}}>0$.

During the primary drying process, the heat transfer medium gives off heat to the product, i.e. $\mathrm{Q}_{\mathrm{WTR}}<0$.

Fig. 3 plots the curve of transferred heat during cooling of the chamber from $15^{\circ} \mathrm{C}$ to $-45^{\circ} \mathrm{C}$ over the nominal temperature of the process. In addition, the distribution of the transferred heat $\mathrm{Q}_{\mathrm{WTR}}$ is shown before linear regression.

When the transferred heat is known, it is possible to determine the heat transfer between heat transfer medium and shelf surface. In the channel of a shelf, the heat introduced by the heat transfer medium is transferred in four possible directions (upwards, downwards, and through the sides). The heat transition between the inside of the segment and the surface of the shelf, as well as between the inside of the segment and the heat transfer medium, is also determined. These heat flows are shown in Fig. 4.

Fig. 4 introduces new variables: $T_{m}$ defines the mean temperature of the heat transfer medium $[\mathrm{K}], T_{S t}$ is the temperature within the segment $[\mathrm{K}]$ and $T_{W}$ the wall temperature on the plate $[\mathrm{K}]$.

The heat transfer coefficient through convection $\alpha\left[\frac{\mathrm{w}}{\mathrm{m}^{2} \cdot \mathrm{K}}\right]$ and the heat transfer coefficient through heat conduction $\lambda_{\mathrm{St}}\left[\frac{\mathrm{w}}{\mathrm{m} \cdot \mathrm{K}}\right]$ are material values of the heat transfer medium.
In addition, $Q_{1}$ defines the heat flow on the channel sides between the heat transfer medium and the inside of the segment [W], $Q_{2}$ the heat flow between the inside of the segment and the surface of the shelf [W] and $Q_{3}$ the vertical heat flow between the heat transfer medium and the surface of the shelf [W].

The cooling of the freeze-dryer chamber is now tested, where the heat transfer medium is regarded as a system and the following assumptions are made in addition: the temperature distribution over the plates is uniform and the process is stationary.

According to the heat balance:

Heat flow $Q_{3}$ is made up of convection and heat conduction between the heat transfer medium and the plate surface and is:

$$
\mathrm{Q}_{3}=\frac{1}{\left(\frac{1}{\alpha}+\frac{\mathrm{s}}{\lambda_{\mathrm{St}}}\right)} \cdot \mathrm{A}_{\mathrm{K}} \cdot\left(\mathrm{T}_{\mathrm{W}}-\mathrm{T}_{\mathrm{m}}\right)
$$

$A_{k}=b \cdot L_{k}\left[\mathrm{~m}^{2}\right]$ is the contact surface area of $Q_{3}$.

Heat flow $Q_{1}$ is made up of convection and heat conduction between the heat trans-

$$
\mathrm{Q}_{\mathrm{WT}}=2 \mathrm{Q}_{3}+2\left(\mathrm{Q}_{1}+\mathrm{Q}_{2}\right) \Leftrightarrow \frac{1}{2} \mathrm{Q}_{\mathrm{WT}}=\mathrm{Q}_{3}+\mathrm{Q}_{1}+\mathrm{Q}_{2}
$$

fer medium and the inside of the segment and is

$$
\mathrm{Q}_{1}=\frac{1}{\left(\frac{1}{\alpha}+\frac{\mathrm{a}}{2 \cdot \lambda_{\mathrm{St}}}\right)} \cdot \mathrm{A}_{1} \cdot\left(\mathrm{T}_{\mathrm{St}}-\mathrm{T}_{\mathrm{m}}\right)
$$

$A_{1}=\alpha \cdot L_{k}\left[\mathrm{~m}^{2}\right]$ is the contact surface area of $Q_{1}$.

Heat flow $Q_{2}$ derives from heat conduction between the inside of the segment and the shelf surface and is:

$$
Q_{2}=\frac{\lambda_{S t}}{\frac{1}{2} s_{S t}} \cdot A_{1} \cdot\left(T_{W T}-T_{S t}\right)
$$

The heat balance is also applied to the segments. It gives rise to:

$$
2 Q_{1}=2 Q_{2} \leftrightarrow Q_{1}=Q_{2}
$$

If $Q_{1}=Q_{2}=Q$ and $Q$ is expressed as a function of $\left(T_{W}-T_{m}\right)$, this gives rise to Eqn. 7:

$$
\mathrm{Q}=\frac{1}{\left(\frac{1}{\alpha}+\frac{\mathrm{a}+\mathrm{s}}{\lambda_{\mathrm{St}}}\right)} \cdot \mathrm{A}_{1} \cdot\left(\mathrm{T}_{\mathrm{W}}-\mathrm{T}_{\mathrm{m}}\right)
$$

Eqn. 2 then becomes:

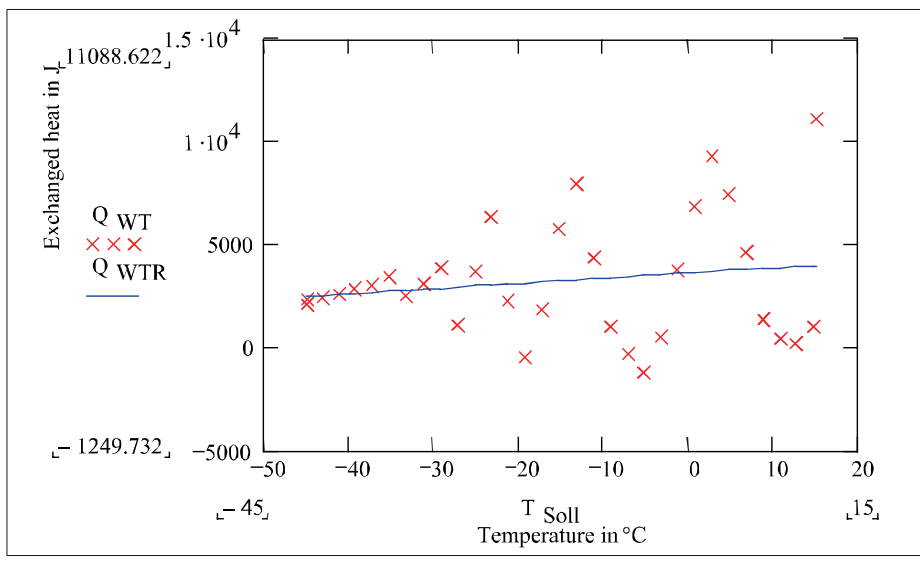

Fig. 3. Comparison of transferred heat before and after the linear regression

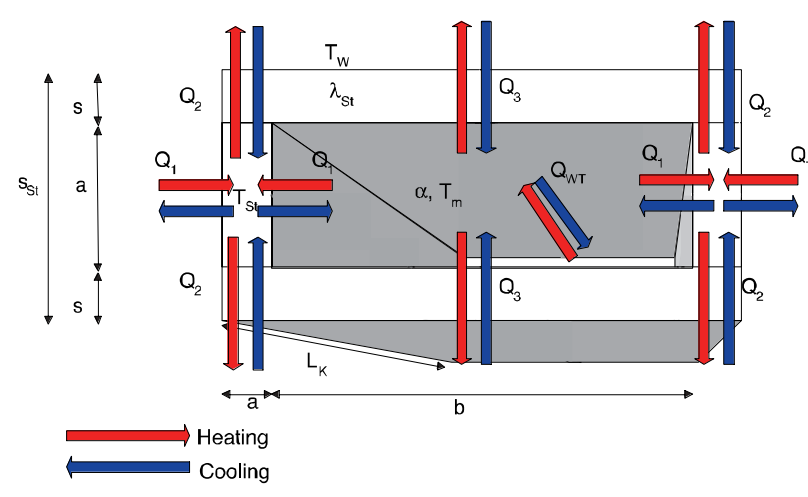

Fig. 4. Heat flows within shelf channel 


$$
\frac{1}{2} \mathrm{Q}_{\mathrm{WT}}=\mathrm{Q}_{3}+2 \mathrm{Q}
$$

and leads to the following result:

$$
\frac{1}{2} \mathrm{Q}_{\mathrm{WT}}=\left[\frac{1}{\left(\frac{1}{\alpha}+\frac{\mathrm{s}}{\lambda_{\mathrm{St}}}\right)} \cdot \mathrm{A}_{\mathrm{K}}+\frac{1}{\left(\frac{1}{\alpha}+\frac{\mathrm{a}+\mathrm{s}}{\lambda_{\mathrm{St}}}\right)} \cdot \mathrm{A}_{1}\right] \cdot\left(\mathrm{T}_{\mathrm{W}}-\mathrm{T}_{\mathrm{m}}\right)
$$

The aim of this calculation is to determine heat transfer coefficient $\alpha$.

Transformation of Eqn. 9 finally gives rise to:

$$
\alpha=\frac{1}{2} \frac{\mathrm{Q}_{\mathrm{WT}}}{\left(\mathrm{T}_{\mathrm{W}}-\mathrm{T}_{\mathrm{m}}\right)} \frac{1}{\left.\frac{1}{\left(1+\frac{\alpha \cdot \mathrm{s}}{\lambda_{\mathrm{St}}}\right)} \cdot \mathrm{A}_{\mathrm{K}}+\frac{1}{\left(1+\frac{\alpha \cdot(\mathrm{a}+\mathrm{s})}{\lambda_{\mathrm{St}}}\right)} \cdot \mathrm{A}_{1}\right]}
$$

Following iteration using Mathcad $^{\circledR}$ 2000 software, the curve of the $\alpha$ value plotted in Fig. 5 is produced during cooling of the chamber from 15 to $-45^{\circ} \mathrm{C}$.

Fig. 5 shows that the $\alpha$ value of 214 $\frac{\mathrm{w}}{\mathrm{m}^{2} \cdot \mathrm{K}}$ at $-45^{\circ} \mathrm{C}$ rises to $792 \frac{\mathrm{w}}{\mathrm{m}^{2} \cdot \mathrm{K}}$ at $15^{\circ} \mathrm{C}$.

The curve of the heat transfer coefficient was produced in a temperature range of $-45^{\circ} \mathrm{C}$ to $+15^{\circ} \mathrm{C}$, but the formula applies approximately also outside these limits for all shelves with rectangular channels. However, the formula does not apply at the margins of the plates, because the heat flows there are no longer identical on the left and right.

It also has to be pointed out that two further assumptions were made for the calculation:

Firstly, $\Delta \mathrm{T}_{\log }=\mathrm{T}_{\mathrm{w}}-\mathrm{T}_{\mathrm{m}}$ was assumed and secondly the calculation was made on the basis of a long straight channel, i.e. deviations were not taken into account and thus a mean $\alpha$ value was derived in the channel.

The determined $\alpha$ values of $214 \frac{\mathrm{w}}{\mathrm{m}^{2} \cdot \mathrm{K}}$ at $-45^{\circ} \mathrm{C}$ and $792 \frac{\mathrm{w}}{\mathrm{m}^{2} \cdot \mathrm{K}}$ at $15^{\circ} \mathrm{C}$ are realistic and lie in the same order of magnitude compared with the values determined in earlier studies.

This study is to be seen as a partial contribution to the complete study of heat transition between heat transfer medium and product within the vials. Other optimization potentials can be found in the improvement of contact between the vials and the plates and also in the knowledge of heat transition between vials and product.

\section{Symbols:}

a Height of channel/thickness of channel wall [m]

$\mathrm{A}_{1} \quad$ Contact surface area of $\mathrm{Q}_{1} \quad\left[\mathrm{~m}^{2}\right]$

$\mathrm{A}_{\mathrm{K}} \quad$ Cross-sectional area of channel[ $\left.\mathrm{m}^{2}\right]$

$\mathrm{b}$ Width of channel [m]

Cp Specific heat [J/(kg.K)]

$\mathrm{L}_{\mathrm{K}}$ Total length of channel [m]
$\mathrm{M}_{\mathrm{Pl}} \quad$ Mass flow

$Q$ Heat flow

$\mathrm{Q}_{1} \quad$ Heat flow on channel sides between heat transfer medium and inside of segment [W]

$\mathrm{Q}_{2} \quad$ Heat flow between inside of segment and surface of shelf.

$\mathrm{Q}_{3} \quad$ Vertical heat flow between heat transfer medium and surface of shelf

$\mathrm{Q}_{\text {WTR }}$ Corrected transferred heat

$\mathrm{Q}_{\mathrm{WT}}$ Transferred heat

$\mathrm{s}$ Sheet thickness of base plates [m]

$\mathrm{s}_{\mathrm{St}}$ Total height of shelf [m]

$\mathrm{T}$ Temperature [K]

$\mathrm{T}_{\text {AusR }}$ Corrected output temperature $[\mathrm{K}]$

$\mathrm{T}_{\text {EinR }}$ Corrected input temperature [K]

$\mathrm{T}_{\mathrm{m}}$ Mean temperature of heat transfer medium

$\mathrm{T}_{\mathrm{St}} \quad$ Temperature inside segment. [K]

$\mathrm{T}_{\mathrm{W}} \quad$ Wall temperature on shelf. [K]

$\Delta \mathrm{T}_{\text {Log }}$ Mean logarithmic temperature difference

$\alpha \quad$ Heat transfer coefficient by convection.

$\lambda_{\mathrm{St}} \quad$ Heat conductivity of steel $[\mathrm{W} /(\mathrm{m} . \mathrm{K})]$

Received: July 2, 2004

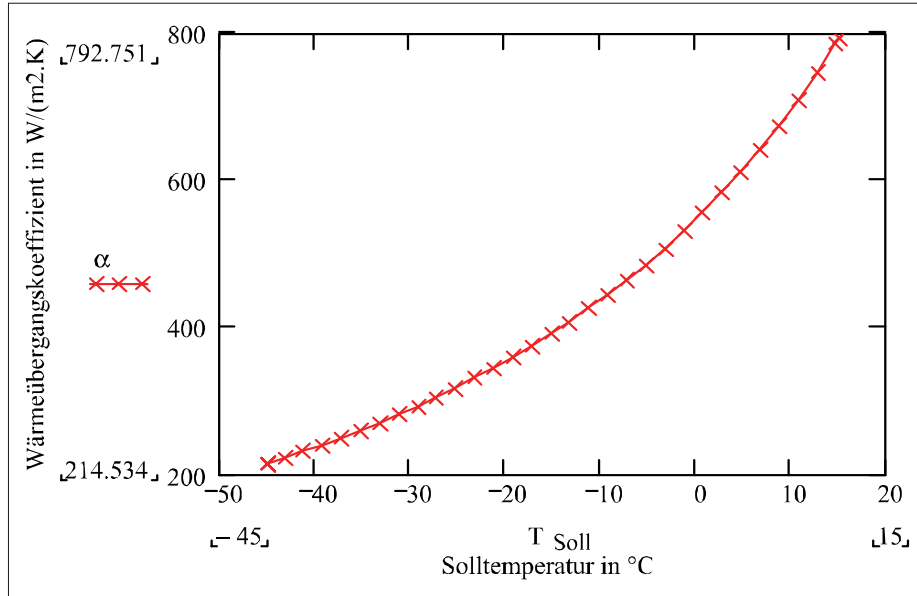

Fig. 5. Curve of $\alpha$ value over the nominal temperature of the progress 


\title{
E. Removal of Glass Tips in Pharmaceutical Production
}

\author{
Roland Chatelain*
}

\begin{abstract}
With the aid of glass tip suction equipment, the glass tips from five ampoule filling machines in different rooms are removed directly from the filling station and conveyed to a special container outside the building. Until now, the glass tips had to be disposed of manually in containers. Whenever the container was replaced by hand, filling machine operations were interrupted. Thanks to the glass tip suction system, the availability of the filling equipment can be improved by about $12 \%$ in terms of production time.
\end{abstract}

Keywords: Removal of glass tips

\section{Background Information}

The sterile filling of up to 1 million ampoules per day generates about $500 \mathrm{~kg}$ of glass tips every day. The containers used until now had to be changed about 34 times per batch, and each replacement meant that machine operations had to be interrupted for $3 \mathrm{~min}$. Thanks to automatic glass tip removal without interruptions to the filling plant, a machine downtime of 102 min can be avoided. The total machine downtime is thus reduced from $>20 \%$ to $<8 \%$. The manual disposal process was expensive and involved long transport routes through several areas. For this reason, a simple and rational solution was sought. Together with Münster Filtersysteme, Plant Engineering SF developed and implemented the following glass tip conveying system.

\section{Description of the System}

On each of the five ampoule filling stations, a glass tip collector was fitted instead of the glass tip container (Fig. 1). Via a piping system (Fig. 2) arranged in the ceiling above the equipment, the ampoule tips are collected and removed to a central container (Fig. 3). The ampoule tips separated by gas burners in the filling equipment (Fig. 4) are thus collected in the container (Fig. 5) outside the building and shipped to the glass manufacturer for recycling.

The aspiration system essentially consists of two radial ventilators each with an input rating of $30 \mathrm{~kW}$, an industrial filter device with automatic cleaning of the filters, a suction pipe system with dual valve discharge and pipe mufflers, the glass tip collector and the control system. Of the two radial ventilators, only one is in operation, and if a malfunction occurs then the system is automatically switched to the second, parallel ventilator.

The filter device with jet pulse cleaning consists of a cylindrical filter housing, a knock-out vessel with crude gas ports welded in, the filter cartridges with inserted injector nozzle, a collecting cone with steep discharge angle to prevent deposits and a discharge system featuring a double gate valve with pneumatic drive.

The dust extraction equipment with jet pulse cleaning is fully automatic, based on the principle of counterpressure. Synchronized pulses of compressed air are fed by an electronic control unit via magnetic valves and injector nozzles into the filter elements. The positive pressure expands the filter and forces the adhering particles of dust out of

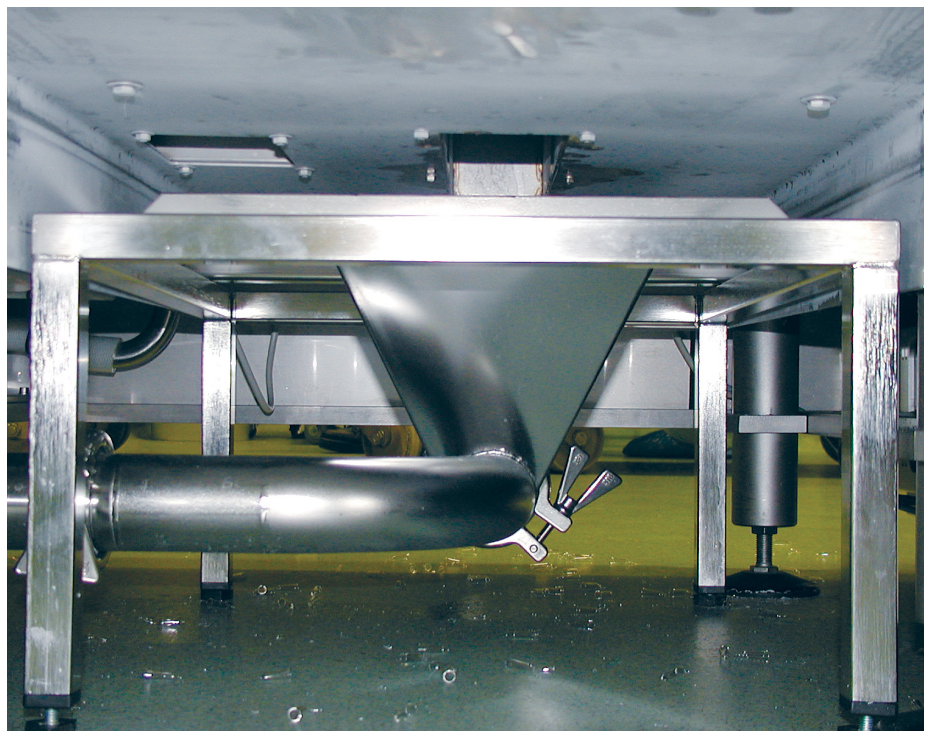

Fig. 1. Glass tip collector under the filling equipment 


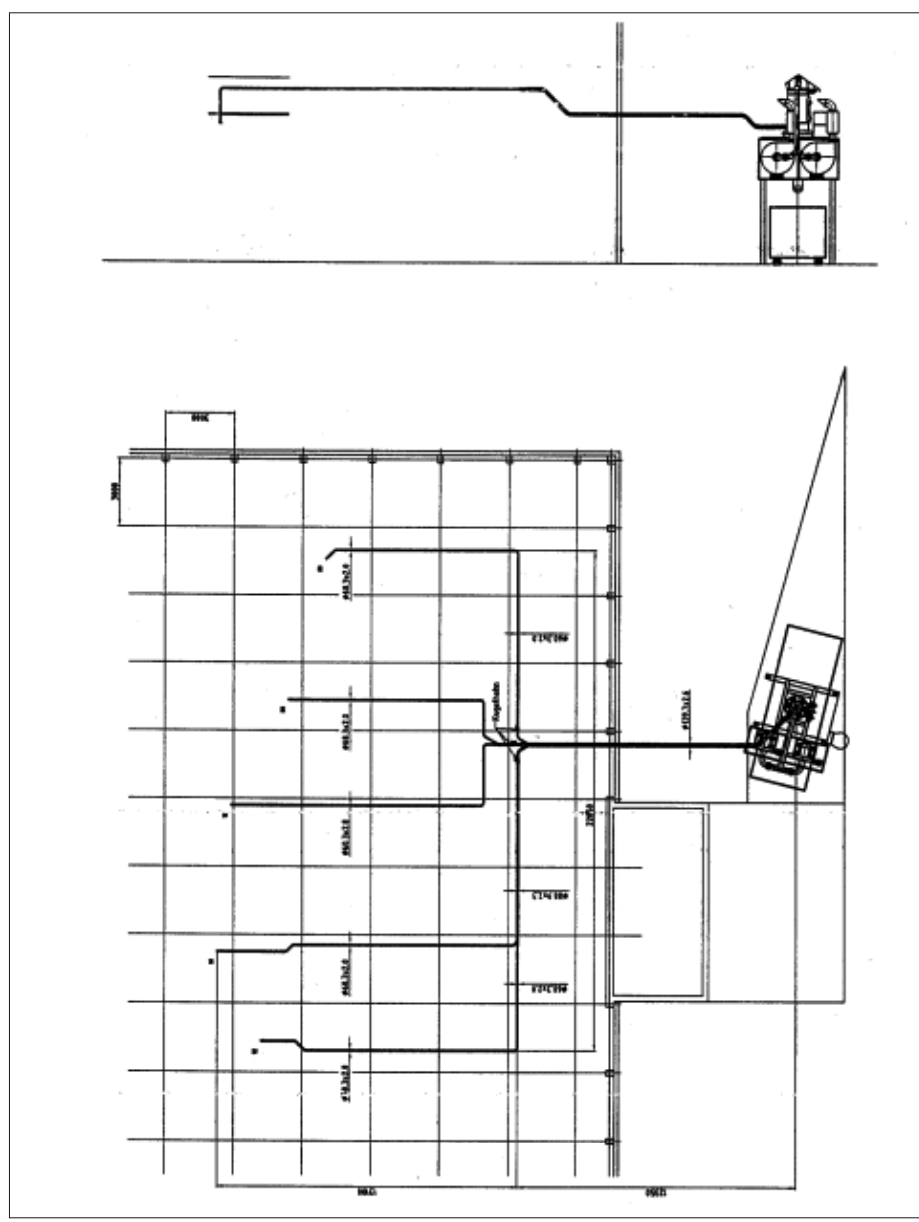

Fig. 2. Suction pipe system laid out above the five filling lines $09,08,11$, 10 and 12

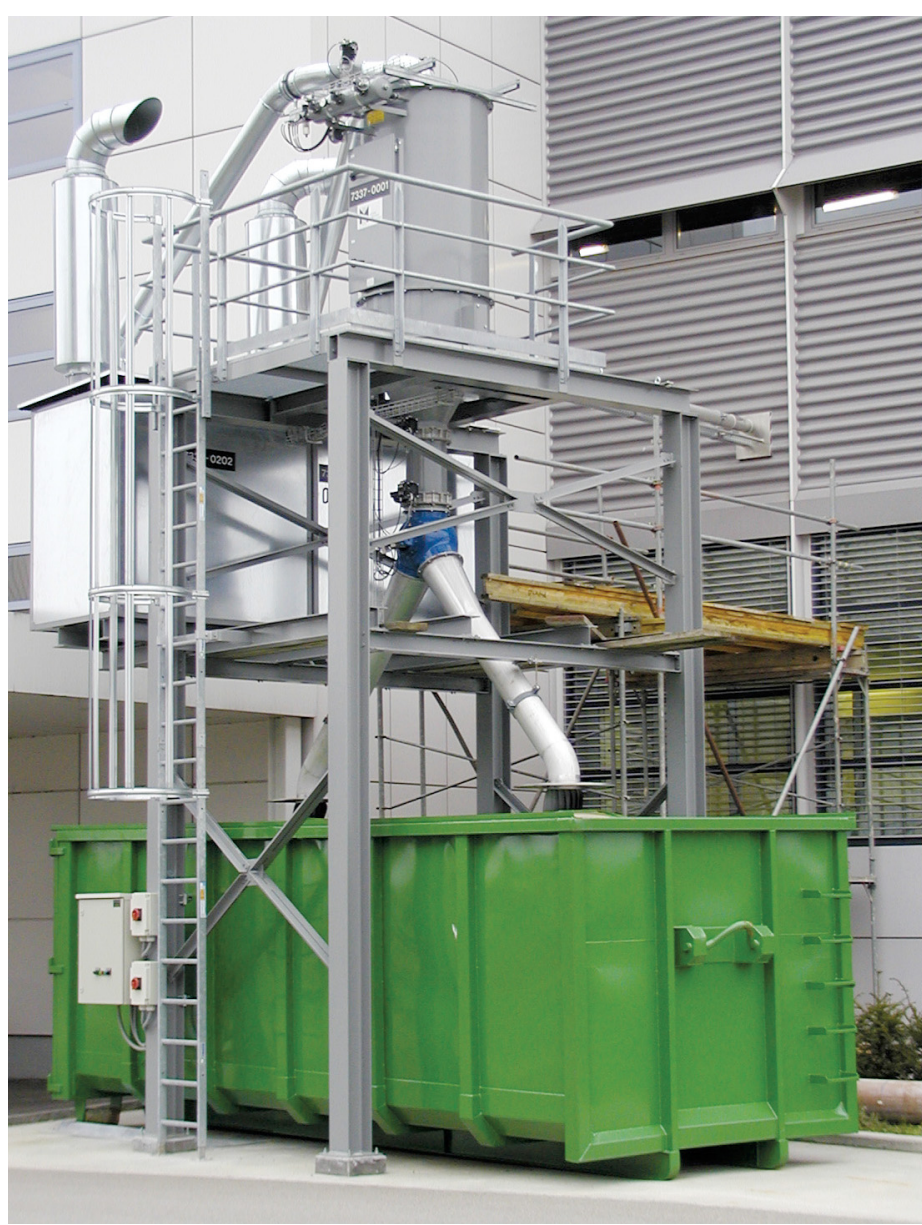

Fig. 3. Glass tip removal set-up outside the production building

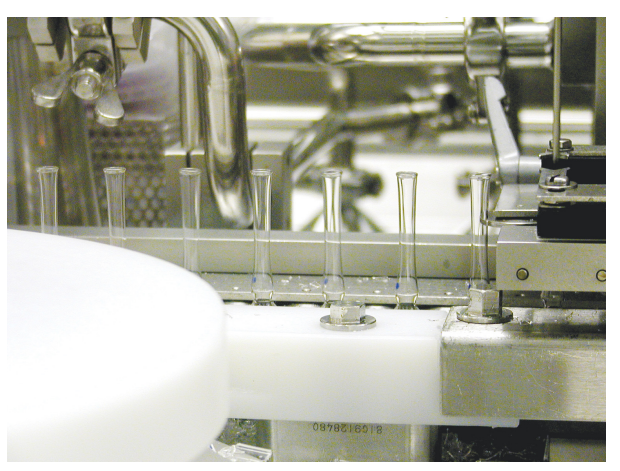

Fig. 4. Glass tips in filling equipment

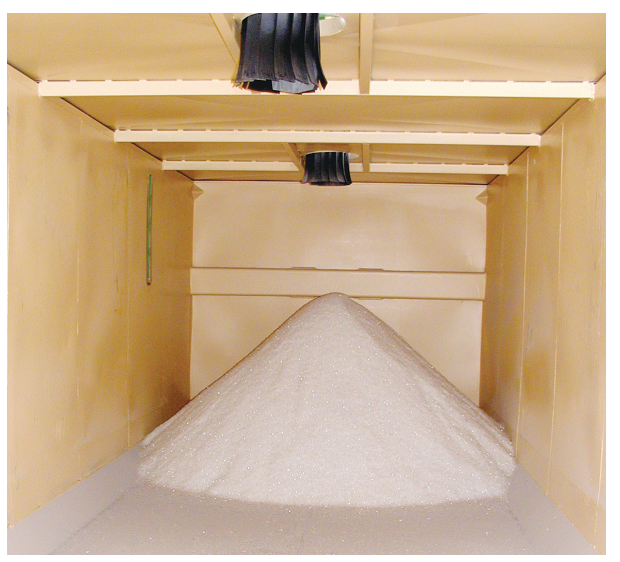

Fig. 5. 'Pulverized' glass tips in the container outside the production building the filter tissue. All parameters such as duration of pulse, pulse frequency, cycle time and duration of follow-up operation are programmable either freely or as a function of differential pressure. When the extraction process is finished, a special follow-up program provides for optimum cleaning of the filter elements.

Five production lines are connected to the glass-tip suction system in three rooms. The suction pipes have a nominal width of $56.3 \mathrm{~mm}$; the total suction cross-section thus amounts to $0.0124 \mathrm{~m}^{2}$. With a suction volume of $1000 \mathrm{~m}^{3} / \mathrm{h}$, the air velocity in the suction pipe is $22 \mathrm{~m} / \mathrm{s}$. The ventilator generates a negative pressure of $16,000 \mathrm{~Pa}$ at the suction port. The input rating is $30 \mathrm{~kW}$. The suction system is currently in continuous operation to keep the air balance of the room ventilation constant. Energy savings are planned, however, to feed the operating mode of the filling machines into the ventilation control for the purpose of ambient pressure adjustment, so that the system can be switched off when all five filling machines are stopped.

The radial ventilator runs at a constant speed. It is not necessary to control the speed with a frequency transformer, because owing to the characteristic curve of the ventilator there is hardly any alteration of pressure when the suction volume flow changes, e.g. on closing of individual suction boxes.

A special feature that has to be mentioned is the question of abrasion. The stainless-steel pipe bend had to be cladded with ceramic oxide because the broken glass causes disintegration of the material on impact in the pipe bend. This disintegration is heavily dependent on velocity. Lowering the speed by a factor of 2 reduces the disintegration of the pipe material by $90 \%$. While the system was originally operated at $45 \mathrm{~m} / \mathrm{s}$, the speed could be reduced by half as a result of optimization. A further speed reduction leads to deposits in the collecting pipe which rises slightly upstream of the jet pulse filter. At an air velocity of $45 \mathrm{~m} / \mathrm{s}$ in the pipe, the glass was crushed to a fine powder by the impact of the glass on the pipe bend, at half the speed the glass is broken into fragments (around 10 per glass tip).

The piping system for the transport of the glass tips is installed above the filling equipment on the engineering floor and carries the glass tips from the five filling machines through individual pipes (outer diameter $60.3 \mathrm{~mm}$ ) into a common suction pipe (outer diameter $139.7 \mathrm{~mm}$ ). The transport distance to the suction system 


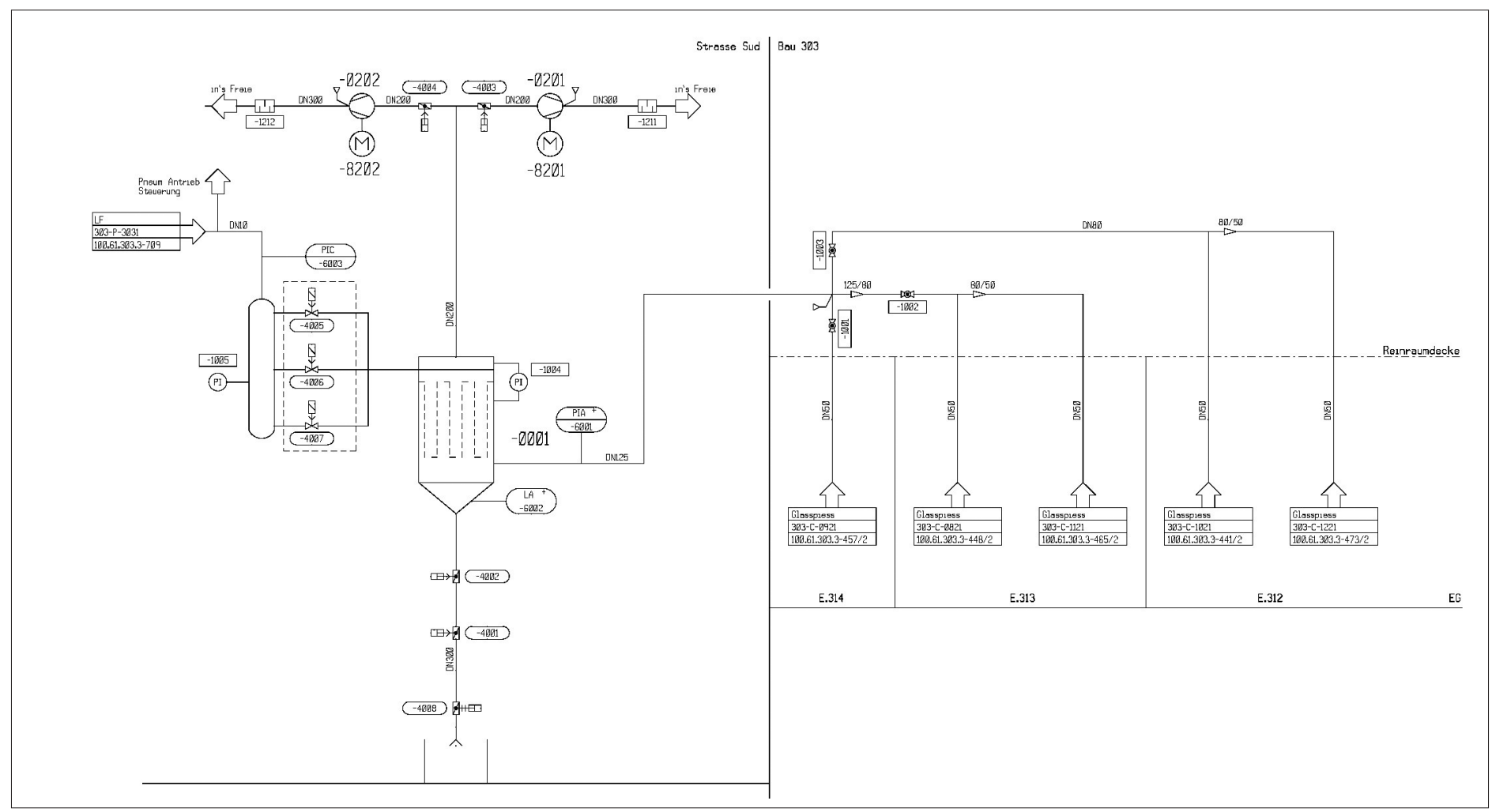

Fig. 6. $\mathrm{P}+\mathrm{I}$ diagramm of the glass tip suction system

outside the building varies, depending on the filling machine, between $30 \mathrm{~m}$ (filling line 8 ) and $43 \mathrm{~m}$ (filling line 12). Fig. 2 shows the suction pipe system in crosssection.

The individual components of the suction system are shown in the $\mathrm{P}+\mathrm{I}$ diagram (Fig. 6).

The present system is a lean-phase system operating in suction or vacuum mode in the low-pressure range (approx. 0.18 bar). The loading of the air is very light, with only about $35 \mathrm{~g}$ glass per kg conveyed air:

\section{Batch size}

Glass tip weight per ampoule

Glass tip weight per batch

Batch process time

Volume flow of aspirated air

Air density

Loading $=$ weight of glass tip/weight of air $=100 \mathrm{~kg} /\left(200 \mathrm{~m}^{3} / \mathrm{h} \times 1.2 \mathrm{~kg} / \mathrm{m}^{3} \times 12 \mathrm{~h}\right)$

$=0.035 \mathrm{~kg}$ glass $/ \mathrm{kg}$ air.

Through the abrasion of glass on the pipe walls, the glass is crushed to a powder during
200,000

mpoules

$100 \mathrm{~kg}$

$12 \mathrm{~h}$

$200 \mathrm{~m}^{3} / \mathrm{h}$

$1.2 \mathrm{~kg} / \mathrm{m}^{3}$

$12 \mathrm{~h})$

pe the conveying process - depending on the conveying speed. As a result, the bulk weight is correspondingly high (window glass has a specific weight of about $2500 \mathrm{~kg} / \mathrm{m}^{3}$ ).

Finally it can be stated that the pneumatic conveyance of glass tips reduces manual handling in GMP zones and thereby increases the quality of the processes. With the reduction in machine downtime, however, the productivity is also increased. The automation of the glass tip removal process is thus doubly rewarding.

Received: July 12, 2004 